\title{
Coronary Artery Bypass Graft Surgery at the University Hospital of the West Indies, Jamaica: Analysis of Clinical Characteristics, Mortality and Length of Hospital Stay CD McGaw $^{1}$, CA Walters ${ }^{2}$, RW Irvine ${ }^{1}$, MD Scarlett ${ }^{1}$, J Blidgen ${ }^{1}$, K Ehikhametalor ${ }^{1}$, PJ Toppin ${ }^{1}$, S Little $^{1}$, S Stephenson ${ }^{1}$, PS Ramphal ${ }^{3}$, HW Spencer ${ }^{4}$
}

\begin{abstract}
Objectives: A detailed analysis of coronary artery bypass graft (CABG) surgical cases performed at the University Hospital of the West Indies (UHWI) has never been conducted. We present the demographic profile, clinical characteristics, and outcome of cases performed during the period March 2010 to March 2016.

Methods: Data from consecutive CABG surgeries performed during the study period were collected prospectively, entered into a computerized database and then analyzed. Outcome measures were 30-day operative mortality, ICU length of stay (ICU LOS) and total postoperative length of stay (PostOp LOS).

Results: Of the 190 patients comprising the study population, $68.9 \%$ were males, and mean age (SD) was $61.3( \pm 10.2)$ years. The most frequent co-morbidities and risk factors were hypertension $(82.1 \%)$ and diabetes (55.3\%), cigarette smoking (33.7\%) and hyperlipidaemia (89\%). Left ventricular ejection fraction (LVEF) was found to be grades 1(good), 2(moderate), and 3(poor) in 50\%, 44.2\%, and 5.8\% of patients, respectively. The majority (83\%) were diagnosed with triple vessel disease. The crude, unadjusted 30-day mortality rate was $8.4 \%$. Using the Canadian Risk Index Model, the mortality rates were: low risk (0-3), 5.5\%; medium risk (4-7), 14.3\%; and high risk ( $\geq 8), 100 \%$. The median ICU LOS and median postoperative LOS were 3 days (IQR, 2-4), and 8 days (IQR, 6-11), respectively. Logistic regression analysis revealed that grade $2 \mathrm{LVEF}$ and urgent/emergent operations were predictors of mortality, female gender predictive of prolonged ICU LOS, and advanced age and female gender of borderline significance for prolonged PostOp LOS.
\end{abstract}

Conclusion: This analysis of outcome of CABG cases performed at the UHWI provides an indication of current performance and serves as a benchmark against which future studies may be compared to determine the efficacy of future quality improvement initiatives.

Keywords: Clinical characteristics, coronary artery bypass graft surgery, University Hospital of the West Indies, outcomes

From: ${ }^{1}$ Department of Surgery, Radiology, Anaesthesia and Intensive Care, Faculty of Medical Sciences ${ }^{2}$ Health Research Resource Unit, Office of the Dean, Faculty of Medical Sciences, Mona, ${ }^{3}$ UWI School of Medicine and Research, Nassau, Bahamas. ${ }^{4}$ Dept of Surgery, Radiology, Anaesthesia and Intensive Care, UWI, Mona, Kingston, Jamaica.

Correspondence: Dr CD McGaw, Department of Surgery, Radiology, Anaesthesia and Intensive Care. The University of the West Indies, Mona, Kingston, Jamaica, West Indies E-mail: cdmcgaw@cwjamaica.com or Clarence.mcgaw@uwimona.edu.jm 


\section{INTRODUCTION}

Coronary artery bypass graft (CABG) surgery was not available in Jamaica until 1994 when the first CABG was performed at the University Hospital of the West Indies (UHWI) by a visiting cardiac surgeon assisted by local medical personnel (1). Subsequent cases were performed on a limited basis by both local and/or visiting surgical teams until around the turn of the millennium when cases began to be performed regularly and exclusively by local providers. Meanwhile, in the developed world, a demand for public reporting of clinical outcomes data had grown exponentially, attributable to the large number of CABG cases being performed, the relatively high mortality rates associated with cardiac surgery, and the wide variation in outcomes between hospitals and caregivers (2). This pressure for greater transparency in quality of care has not spared healthcare teams in developing countries as they are likewise expected to publish their outcomes data. This study is the first detailed analysis of the demographic profile, clinical characteristics and outcomes in relation to mortality rate and length of hospital stay of CABG cases performed at the UHWI since being performed entirely by local medical personnel. Benchmarking of such outcomes data will enable a comparison of results when future studies are carried out to evaluate the efficacy of current and future quality-of-care improvement initiatives.

\section{SUBJECTS AND METHODS}

The UHWI is a 500-bed, tertiary care teaching institution, affiliated with the University of the West Indies, and located in Kingston, the capital city of Jamaica. It is the only institution in Jamaica where adult open heart surgery is performed and, therefore, the data obtained from this study represent the data for the entire country of Jamaica. Only patients who had isolated CABG 
surgery were included in this study. The data was collected prospectively on consecutive patients who had isolated CABG between March 2010 and March 2016, was subsequently entered into a computerized database (SPSS, version 17), and then analyzed. Approval for the study was granted by the Ethics Committee of the University of the West Indies.

The outcomes of interest were 30-day operative mortality, ICU length of stay (ICU LOS), and postoperative length of stay (PostOp LOS) - including the days in ICU. Mortality is generally considered to be operation-related if it occurred during the same hospitalization or within 30 days after surgery, regardless of venue.

\section{Statistical analyses}

Patient characteristics and outcomes were summarized as frequencies and percentages. Length of ICU and hospital stay were reported as mean $+/$ - standard deviation if data distribution did not deviate significantly from normality and median (interquartile range or IQR) if they did. Continuous variables were analyzed using the student's t-test or Mann-Whitney U test and categorical variables analyzed using the chi-square test or Fisher's exact test, as appropriate. Univariate and multi-variate logistic regression models were generated to quantify risk for 30day mortality, very long ICU LOS (more than 3 days) and very long PostOp LOS (more than 8 days). P-values below 0.05 were considered statistically significant. Stata Version 13.1 statistical package was used for statistical analysis.

Predicted mortality was assessed preoperatively using the Canadian Risk Index (CA) model (3). We chose this model for its simplicity, accuracy and reliability (4). This predictive model utilizes six variables: age, sex, left ventricular function, urgency of surgery, repeat operation and type of surgery (Table 1). The definition of the variables used in this study are identical with those used in the studies conducted by Tu et al: emergency surgery is defined as 
operation required within 24 hours, while urgent surgery is surgery recommended in the index hospitalization $(3,4)$. For this study, 'isolated' CABG outcomes, one variable (type of surgery) was set to its null value, leaving only 5 variables and their associated risk scores.

\section{RESULTS}

Characteristics of participants included in the analyses are shown in Table 2. One hundred and ninety (190) patients underwent isolated, primary CABG surgery during the study period; none were repeat operations. They were predominantly male (68.9\%), and ranged in ages between 30 and 84 years, with a mean (SD) of 61.3 (10.2) (Table 2). There was a high incidence of hypertension (82.1\%) and diabetes (55.3\%), and $51.1 \%$ of patients were both hypertensive and diabetic. Left ventricular function - based on ejection fraction as assessed by echocardiography (LVEF) was Grade 2 and Grade 3 in $44.2 \%$ and $5.8 \%$ of patients, respectively.

\section{Operative and postoperative characteristics}

There was an almost equal distribution of elective (53.2\%) and urgent (42.6\%) operations (Table 3). The median cardiopulmonary bypass (CPB) and cross clamp times were 152 and 83 minutes, respectively. Almost one-half (49.2\%) of the patients had a triple vessel bypass procedure, while another 37.4\% had quadruple vessel bypass. Median ICU LOS and PostOp LOS were 3 and 8 days, respectively.

\section{Outcomes}

The crude overall 30 -day mortality rate was $8.4 \%$. When stratified according to CA risk groups, the mortality rates were: low risk (0-3), 5.5\%; medium risk (4-7), 14.3\%; and high risk $(=>8)$, $100 \%$ (Table 4a). However, note that only 2 of the 190 study patients were categorized as high 
risk, each with a CA risk score of 8 . The lowest risk category of patients, i.e., those with scores of $0-1$, had a very low mortality rate of $1.4 \%$. Generally, higher risk scores were associated with higher mortality rates (Table $4 \mathrm{~b}$ ). Patients with no risk factors, i.e., 30 patients, had a $0 \%$ mortality rate (Table 4b). Higher risk scores were also predictive of longer ICU and PostOp length of stays $(p=.0015$ and $p=.0023$ respectively).

Logistic regression analysis carried out on predictors of 30-day mortality showed an increased risk among: older age groups $(\mathrm{p}=.057)$; grade II LVEF $(\mathrm{p}=.014)$ and grade III LVEF $(p=.351) ;$ urgent $(p=.009)$ and emergent $(p=.001)$ surgery, when compared with younger patients, grade 1 LVEF patients, and elective cases, respectively. There was almost a three-fold increased risk for prolonged ICU LOS among females $(\mathrm{p}=.002)$. Compared to each reference category, increased risks were seen throughout for prolonged PostOp LOS. Significantly increased risk for 30-day mortality among urgent $(\mathrm{p}=.012)$ and emergent $(.005)$ surgery compared to elective cases was retained in the multivariate model (not shown); as was the threefold increased risk for prolonged ICU LOS among females $(\mathrm{p}=.002) \quad$ (Table 5).

\section{DISCUSSION}

Despite operating on an older and sicker population, CABG surgery has seen a remarkable improvement in outcome since the high mortality rates associated with the procedure in the initial phase of its history (5). Currently, mortality rates for isolated primary CABG range between $1-3 \%(6,7)$. Although these low mortality rates have been achieved primarily at leading medical centers in the world, they now constitute the 'gold standard' or benchmark for outcomes wherever in the world CABG surgery is performed. In an audit carried out by Scarlett et al on all 
cardiac cases performed at the UHWI up to 2003 an overall mortality rate of $21 \%$ was reported for CABG cases. However, the study was retrospective, small volume (91 patients), and used only NYHA score for risk assessment; $72 \%$ of cases were NYHA III/IV and accounted for all the mortality.

In this study, the overall (crude) mortality rate of $8.4 \%$, while exceeding the 'gold standard', compares favorably with that reported in some developing countries and unfavorably with others (8-11). de Oliveira et al, in their study on a Southern Brazilian population undergoing CABG surgery between 2002 and 2010, reported a relatively high overall mortality rate of $12.1 \%$ (8). Likewise, Jamaati et al., in their study on Iranian patients between 2004 and 2010 , reported a mortality rate of $12.2 \%$ (9). On the other hand, Saifuddin $e t$ al, in their study at the Aga Khan University (Pakistan) on 2198 cases performed between 2006 and 2010, reported an overall 30-day mortality of only $2.7 \%$ (10). Also, Seethararaman et al, in their study conducted between 2003 to 2008 in Trinidad and Tobago (T\&T), reported a low mortality rate of $1.2 \%(11)$.

The marked disparity in mortality outcomes reported in our study $(8.4 \%)$ and the T\&T study warrants further elucidation, considering the many similarities between both countries and small populations (Jamaica, $2.7 \mathrm{~m} ; \mathrm{T} \& \mathrm{~T}, \sim 1.4 \mathrm{~m}$ ) geographic location (Caribbean Sea), historical background (former British colonies) (12). Three factors which may be contributory towards this disparity are: the volume of cases, the operative technique, and the actual quality of care.

\section{Volume of cases}

The Trinidad and Tobago study was comprised of 1082 cases versus 190 cases in our study, both collated over a similar time span. The impact of volume of cases on mortality rate can be 
significant as many studies have reported an inverse relationship between high volume of cases and mortality rate $(13,14)$. This phenomenon may be explained by the well-known adage, 'practice makes perfect'. However, some more recent studies have reported excellent results at many low volume centres, suggesting that an inverse volume-mortality rate relationship is not immutable (15). The message from this study is that concerted and consistent focus on quality can compensate for lower case volumes in determining outcome in CABG surgery. There is yet another means by which difference in volume of cases may skew mortality rates in favour of larger volumes. Marcin et al. explain that outcome measurements and risk adjustment are statistical procedures that rely on large sample sizes to produce risk estimates and outcome interpretations that are trustworthy, eg observed outcome rates are less likely to be skewed by outliers in the case of high-volume providers than in the case of low-volume providers $(16,17)$.

\section{Operative technique}

In the T\&T study, Hariharan et al state that the proportion of cases they do off-pump have steadily increased from $50 \%$ in 2002 to a current level of $80-85 \%$, and further that, in a previous study, they found the overall mortality rate for off-pump CABG (OPCAB) surgeries during the period 1997 to 2002 was $2.6 \%$ compared with $4.6 \%$ for OPCAB (11),17). Whether OPCAB confers an early or long-term clinical advantage to conventional CPB remains controversial. Some studies support an advantage for OPCAB while others do not $(19,20)$. In an effort to resolve the conflicting results, Yadava and Kundu carried out a review on many of the seminal studies on the issue, and concluded that the problem lies, not with the technique, but with the surgeon, and that the best technique is that which works best for that particular patient, in the context of his clinical setting and his treating surgeon's repertoire (21). 


\section{Quality of care}

In the Trinidad and Tobago study, the surgeries were performed by visiting cardiac teams, mostly from developed countries, assisted by local providers, unlike in Jamaica where they were carried out entirely by local providers. To what extent this translates into differences in quality of care and outcomes is difficult to determine. Evaluation of quality of care is a complex process as quality is a fluid and abstract concept. When assessing quality of care, it is important to consider all pre, peri and post-operative variables (22). Regardless, as important as performance comparisons between institutions may be, of greater import is the need for each institution to identify areas of their respective service which may be amenable to quality-of-care improvement initiatives. To this end, an analysis of structure, process and outcome variables must be carried out according to the method initially presented by Donabedian and later expanded on by Birkmeyer $(23,24)$. Various studies have confirmed the positive effect of quality improvement programs on mortality and morbidity outcomes for surgical procedures generally and for cardiac surgery, specifically $(25,26)$.

Our median ICU LOS (3 days) and median PostOp LOS (8 days) were comparable with international standards. Bridgewater et al, in their study utilizing data from 366 hospitals in 29 countries reported a median PostOp LOS after isolated CABG of 7 days, but varies from 4.5 days up to 11 days between countries (7). The median PostOp LOS was 5 days in the UK, and 9 days in France (7).

\section{Limitations}

Firstly, our sample size was small relative to other previously published studies. Also, while the CA risk index is simple, accurate and reliable, there is a possibility that other models may provide more precise stratification of risk as the prevalence and importance of certain risk factors 
may be different in different settings. Future studies comparing different models will be required to satisfy this issue. Regarding mortality rates, other peri-operative factors, e.g., aortic crossclamp time, and post-surgical quality of care could impact on patient outcome. Likewise, hospital length of stays may be skewed as a result of differing discharge protocols between institutions, $e g$ at the UHWI, there is both a mandatory minimum ICU stay of 2 days due to the lack of a well-developed high dependence unit, as well as a tendency to prolong postoperative hospitalization as many patient live in rural environments with inadequate medical and transportation facilities.

\section{CONCLUSION}

This study provides the first benchmark for 30-day operative mortality for CABG surgery cases performed at the UHWI exclusively by local medical personnel. Such data are required to provide an indicator of current performance; to assist prospective patients and their physicians in deciding whether to have their CABG surgery at the UHWI or elsewhere; to guide local policy makers in the implementation of quality of care improvement initiatives; and to provide a baseline against which future studies may compare outcomes in order to determine the efficacy of whatever quality of care initiatives are instituted.

\section{ACKNOWLEDGEMENTS}

The authors wish to thank the many cardiologists who care for and refer our patients in a timely manner, our cardiopulmonary perfusionists, Dorothy Pinnock and Fitzhugh Forrest, for their 
expert care during the operations, and Kaodi McGaw for compiling the references using the Mendeley citation manager software. 


\section{REFERENCES}

1. Scarlett MD, McGaw CD, Ramphal PS, Irvine RW, Spencer HW. Thirty-five years of cardiac surgery in Jamaica. West Indian Med J. 2004; 53: 178-83.

2. Hannan EL, Kilburn H, O’Donnell JF, Lukacik G, Shields EP. Adult open heart surgery in New York State. An analysis of risk factors and hospital mortality rates. JAMA 1990; 264: 2768-74. Available from: http://www.ncbi.nlm.nih.gov/pubmed/2232064

3. Tu JV, Jaglal SB, Naylor CD. Multicenter Validation of a Risk Index for Mortality, Intensive Care Unit Stay, and Overall Hospital Length of Stay After Cardiac Surgery. Circulation 1995; 91: 677-84. Available from: tp://circ.ahajournals.org/content/91/3/677.short

4. Tu JV, Sykora K, Naylor CD. Assessing the Outcomes of Coronary Artery Bypass Graft Surgery: How Many Risk Factors Are Enough? J Am Coll Cardiol 1997; 30: 1317-23. Available from: http://www.sciencedirect.com/science/article/pii/S0735109797002957

5. Ferguson TB, Hammill BG, Peterson ED, DeLong ER, Grover FL, Committee STSND. A decade of change-risk profiles and outcomes for isolated coronary artery bypass grafting procedures, 1990-1999: a report from the STS National Database Committee and the Duke Clinical Research Institute. Ann Thorac Surg. 2002; 73: 480-9.

6. Head SJ, Kieser TM, Falk V, Huysmans HA, Kappetein, AP. Coronary artery bypass grafting: Part 1--the evolution over the first 50 years. Eur Heart J 2013; 34: 2862-72. Available from: http://www.ncbi.nlm.nih.gov/pubmed/24086085

7. Bridgewater B, Gummert J, Walton P, Kinsman R. Fourth EACTS Adult Cardiac Surgical Database Report. Clinical Database Reports. 2010: 1-10. Available from: 
http://scholar.google.com/scholar?hl=en\&btnG=Search\&q=intitle:Fourth+EACTS+Adult + Cardiac + Surgical+Database+Report\#2

8. De Oliveira EL, Westphal GA, Mastroeni MF. Demographic and clinical characteristics of patients undergoing coronary artery bypass graft surgery and their relation to mortality. Brazilian J Cardiovasc Surg 2012; 27: 52-60.

9. Jamaati H, Najafi A, Kahe F, Karimi Z, Ahmadi Z, Bolursaz M, et al. Assessment of the EuroSCORE risk scoring system for patients undergoing coronary artery bypass graft surgery in a group of Iranian patients. Indian J Crit Care Med 2015; 19: 576-9.

10. Saifuddin A, Shahabuddin S, Perveen S, Furnaz S, Sharif H. Towards excellence in cardiac surgery: Experience from a developing country. Int J Qual Heal Care 2015; 27: $255-9$.

11. Hariharan S, Chen D, Vialva M, Exeter H, Billingy I, Bobb K-A et al. Outcome evaluation of coronary artery bypass grafting surgery applying the EuroSCORE in a Caribbean developing country. Heart Surg Forum 2010; 13: E287-91.

12. Population Reference Bureau. World Population Data Sheet. World Popul Data Sheet. 2015; August:20.

13. Birkmeyer JD, Siewers AE, Finlayson EVA, Stukel TA, Lucas FL, Batista I et al. Hospital volume and surgical mortality in the United States. N Engl J Med 2002; 346: 1128-37. Available from: http://www.ncbi.nlm.nih.gov/pubmed/11948273.

14. Hannan EL, Wu C, Ryan TJ, Bennett E, Culliford AT, Gold JP et al. Do hospitals and surgeons with higher coronary artery bypass graft surgery volumes still have lower riskadjusted mortality rates? Circulation. 2003; 108: 795-801. 
15. Kurlansky PA, Argenziano M, Dunton R, Lancey R, Nast E, Stewart A, et al. Quality, not volume, determines outcome of coronary artery bypass surgery in a university-based community hospital network. J Thorac Cardiovasc Surg 2012; 143: 287-93.

16. Marcin JP, Li Z, Kravitz RL, Dai JJ, Rocke DM, Romano PS. The CABG surgery volume-outcome relationship: Temporal trends and selection effects in California, 19982004. Health Serv Res 2008; 43: 174-92.

17. Dimick JB, Welch HG, Birkmeyer JD. Surgical mortality as an indicator of hospital quality: the problem with small sample size. JAMA 2004; 292: 847-51. Available from: http://www.ncbi.nlm.nih.gov/pubmed/15315999

18. Hariharan S, Chen D, Merritt-Charles L. Off-pump coronary artery bypass surgery: Anaesthetic implications and the Trinidad experience. West Indian Med J 2006; 55: 298304.

19. Cheng DC, Bainbridge D, Martin JE, Novick RJ. Does off-pump coronary artery bypass reduce mortality, morbidity, and resource utilization when compared with conventional coronary artery bypass? A meta-analysis of randomized trials. Anesthesiology 2005; 102: 188-203. Available from: http://www.ncbi.nlm.nih.gov/pubmed/15618803

20. Puskas JD, Thourani VH, Kilgo P, Cooper W, Vassiliades T, Vega JD et al. Off-pump coronary artery bypass disproportionately benefits high-risk patients. Ann Thorac Surg 2009; 88: 1142-7. Available from: http://dx.doi.org/10.1016/j.athoracsur.2009.04.135

21. Yadava OP, Kundu A. "On” or “Off” pump coronary artery bypass grafting - Is the last word out? Indian Heart J 2013 Mar; 65: 187-90. Available from: http://www.ncbi.nlm.nih.gov/pmc/articles/PMC3861129 
22. Noyez L, Kievit PC, Verkroost MWA, Van Wetten HB, Verhagen AFTM, Van Swieten HA. Evaluation of quality in adult cardiac surgery: Let us speak the same language. Netherlands Hear J 2010; 18: 365-9. Available from: http://www.scopus.com/inward/record.url?eid=2-s2.077957667362\&partnerID=40\&md5=391b8a59f9c2c047db90ef7864302d25

23. Donabedian A. Evaluating the quality of medical care. Milbank Q 1966; 44:166-203. Available from: ttp://www.pubmedcentral.nih.gov/articlerender.fcgi?artid=2690293\&tool=pmcentrez\&re ndertype $=$ abstract

24. Birkmeyer JD, Dimick JB, Birkmeyer NJO. Measuring the quality of surgical care: Structure, process, or outcomes? Journal of the American College of Surgeons. 2004; 198: $626-32$.

25. Miyata H, Motomura N, Murakami A, Takamoto S. Effect of benchmarking projects on outcomes of coronary artery bypass graft surgery: Challenges and prospects regarding quality improvement initiative. J Thorac Cardiovasc Surg 2012; 143: 1364-69.

26. Hall BL, Hamilton BH, Richards K, Bilmoria KY, Cohen ME, Ko CY. Does surgical quality improve in the American College of Surgeons National Surgical Quality Improvement Program; an evaluation of all participating hospitals. Ann Surg 2009; 250: $363-76$. 
Table 1: Canadian Risk Index

\begin{tabular}{ll}
\hline Variable & Risk score \\
\hline Age & 0 \\
$\quad$ Under 65 & 2 \\
$65-74$ & 3 \\
75 and older & \\
Sex & 0 \\
$\quad$ Male & 1 \\
Female & \\
Left ventricular function & \\
$\quad$ Grade 1 ( $>50 \%)$ & 0 \\
Grade 2 (35 - 50\%) & 1 \\
Grade 3 (20 - 34\%) & 2 \\
Grade 4 (<20\%) & 3 \\
Urgency of surgery & \\
Elective & \\
Urgent & 0 \\
Emergency & 1 \\
Re-operation (previous CABG) & \\
No & \\
Yes & 0 \\
Type of Surgery & 2 \\
CABG only & \\
Single valve & \\
Complex (plus valve) & \\
Maximum score & \\
\hline
\end{tabular}


Table 2: Demographic and Preoperative Clinical Characteristics for Patients undergoing Isolated CABG

\begin{tabular}{|c|c|}
\hline Characteristic & n (\%) \\
\hline Number of patients & 190 \\
\hline \multicolumn{2}{|l|}{ Demographic } \\
\hline Male & $131(68.9 \%)$ \\
\hline \multicolumn{2}{|l|}{ Age (yrs.): } \\
\hline mean $\pm \mathrm{SD}$ & $61.3 \pm 10.2$ \\
\hline Under 65 & $114(60.0 \%)$ \\
\hline $65-74$ & $57(30.0 \%)$ \\
\hline 75 and over & $19(10.0 \%)$ \\
\hline African race/ ethnicity & $139(73.2 \%)$ \\
\hline \multicolumn{2}{|l|}{ Body mass index $\left(\mathrm{kg} / \mathrm{m}^{2}\right)$ : } \\
\hline Overweight (25.0-29.9) & $81(42.9 \%)$ \\
\hline Obese (30.0-34.9) & $12(7.1) 33(17.5 \%)$ \\
\hline Very obese ( 35.0 or more) & $13(6.9 \%)$ \\
\hline \multicolumn{2}{|l|}{ Preoperative CV risk factors } \\
\hline Hypertension & $156(82.1 \%)$ \\
\hline Diabetes Mellitus & $105(55.3 \%)$ \\
\hline Dyslipidaemia & $169(88.9 \%)$ \\
\hline Current smoking & $37(19.5 \%)$ \\
\hline \multicolumn{2}{|l|}{ Past Medical History } \\
\hline Previous CCF & $31(16.3 \%)$ \\
\hline Previous CVA & $18(9.5 \%)$ \\
\hline Previous vascular surgery & $7(3.7 \%)$ \\
\hline Recent MI ( $<3$ months $)$ & $98(52.7 \%)$ \\
\hline Chronic lung disease & $17(8.9 \%)$ \\
\hline Left main trunk stenosis $(>50 \%)$ & $57(30.0 \%)$ \\
\hline \multicolumn{2}{|l|}{ LV EF: } \\
\hline Grade $1(>50 \%)$ & $95(50.0 \%)$ \\
\hline Grade $2(35-50 \%)$ & $84(44.2 \%)$ \\
\hline Grade $3(20-34 \%)$ & $11(5.8 \%)$ \\
\hline Grade $4(<20 \%)$ & --- \\
\hline
\end{tabular}

Abbreviations: $\mathrm{CV}=$ cardiovascular; $\mathrm{CCF}=$ congestive cardiac failure; $\mathrm{CVA}=$ cerebrovascular accident; $\mathrm{MI}=$ myocardial infarction $; \mathrm{LVEF}=$ left ventricular ejection fraction 
Table 3: Patient's intra- and post-operative characteristics

\begin{tabular}{ll}
\hline Characteristic & n (\%) \\
\hline $\begin{array}{l}\text { Operative priority (acuity): } \\
\text { Elective }\end{array}$ & $101(53.2 \%)$ \\
Urgent & $81(42.6 \%)$ \\
Emergent & $8(4.2 \%)$ \\
No. of grafts: & \\
One & $3(1.6 \%)$ \\
Two & $22(11.8 \%)$ \\
Three & $92(49.2 \%)$ \\
Four or more & $70(37.4 \%)$ \\
& \\
CPB bypass time (min.), median (IQR) & $152(132-176)$ \\
Cross-clamp time (min.), median (IQR) & $83(71-99)$ \\
ICU LOS (days), median (IQR) & $3(2-4)$ \\
PostOp LOS (days), median (IQR) & $8(6-11)$ \\
CPB = cardiopulmonary bypass; IQR = interquartile range
\end{tabular}

Table 4a: Mortality rate, ICU LOS and PostOp LOS according to CA risk index groups

\begin{tabular}{lllll}
\hline Risk Score & $\begin{array}{l}\text { Patients } \\
\text { n }(\%)\end{array}$ & $\begin{array}{l}\text { Mortality } \\
\text { n }(\%)\end{array}$ & $\begin{array}{l}\text { Median ICU LOS } \\
\text { d (IQR) }\end{array}$ & $\begin{array}{l}\text { Median PostOp LOS } \\
\text { d (IQR) }\end{array}$ \\
\hline $0-3$ & $146(76.8 \%)$ & $8(5.5 \%)$ & $3(2-4)$ & $7(6-10)$ \\
$4-7$ & $42(22.1 \%)$ & $6(14.3 \%)$ & $3(3-7)$ & $10(7-17)$ \\
8 or more & $2(1.1 \%)$ & $2(100.0 \%)$ & - -- $^{-}$ & - a $^{-}$ \\
\hline
\end{tabular}

Only 2 patients in this category

Mortality $=30$-day mortality

Abbreviations: ICU LOS = length of stay in the intensive care unit; PostOp LOS = total postoperative length of stay (includes ICU LOS)

$\mathrm{d}=$ days; $\mathrm{IQR}=$ interquartile ratio 
Table 4b: Mortality rates according to CA risk index

\begin{tabular}{lllll}
\hline Risk Score & $\begin{array}{l}\text { Patients } \\
\mathbf{n}(\mathbf{\%})\end{array}$ & $\begin{array}{l}\text { Mortality } \\
\mathbf{n}(\%)\end{array}$ & $\begin{array}{l}\text { Median ICU } \\
\text { LOS, d (IQR) }\end{array}$ & $\begin{array}{l}\text { Median PostOp LOS } \\
\mathbf{d}(\mathbf{I Q R})\end{array}$ \\
\hline 0 & $30(15.8 \%)$ & $0(0 \%)$ & $2(2-4)$ & $7.5(5.5-9.5)$ \\
1 & $40(21.1 \%)$ & $1(2.5 \%)$ & $3(2-4)$ & $7(5-9)$ \\
2 & $42(22.1 \%)$ & $4(9.5 \%)$ & $3(2-4)$ & $7(6-10)$ \\
3 & $34(17.9 \%)$ & $3(8.8 \%)$ & $3(2-4)$ & $9(6-13)$ \\
4 & $17(8.9 \%)$ & $3(17.7 \%)$ & $3(3-7)$ & $10.5(7-17)$ \\
5 & $14(7.4 \%)$ & $2(14.3 \%)$ & $3.5(2-6)$ & $10(7-17)$ \\
6 & $8(4.2 \%)$ & --- & $7(3.5-12.5)$ & $11(7.5-45)$ \\
7 & $3(1.6 \%)$ & $1(33.3 \%)$ & $--^{\mathrm{a}}$ & - - $^{\mathrm{a}}$ \\
8 & $2(1.1 \%)$ & $2(100.0 \%)$ & - -- $^{\mathrm{a}}$ & $-{ }^{\mathrm{a}}$ \\
\hline
\end{tabular}

Only 2 patients in this category

Abbreviations: as for previous table

Table 5: Logistic Regression (Univariate) Models for Mortality, ICU LOS and PostOp LOS

\begin{tabular}{|c|c|c|c|c|c|c|}
\hline \multirow[b]{2}{*}{ Risk Factor } & \multicolumn{2}{|l|}{$\begin{array}{l}\text { 30-day } \\
\text { Mortality }\end{array}$} & \multicolumn{2}{|c|}{$\begin{array}{l}\text { Prolonged ICU } \\
\text { LOS }\end{array}$} & \multicolumn{2}{|c|}{$\begin{array}{l}\text { Prolonged PostOp } \\
\text { LOS }\end{array}$} \\
\hline & OR & $p$-value & OR & $p$-value & OR & $p$-value \\
\hline \multicolumn{7}{|l|}{ Age, Y } \\
\hline 65 to 74 & 2.94 & 0.057 & 1.07 & 0.842 & 1.97 & .055 \\
\hline$\geq 75$ & 2.12 & 0.381 & 1.47 & 0.444 & 2.78 & .066 \\
\hline \multicolumn{7}{|l|}{ Sex } \\
\hline Female & 0.72 & 0.586 & 2.82 & 0.002 & 1.92 & .055 \\
\hline \multicolumn{7}{|l|}{ LVEF } \\
\hline Grade 2 & 5.11 & 0.014 & 1.71 & 0.102 & 1.10 & .778 \\
\hline Grade 3 & 3.07 & 0.351 & 2.11 & 0.248 & 3.22 & .106 \\
\hline \multicolumn{7}{|c|}{ Urgency of surgery } \\
\hline Urgent & 7.78 & 0.009 & 0.74 & 0.361 & 1.60 & .144 \\
\hline Emergent & 29.7 & 0.001 & 2.33 & 0.285 & 2.07 & .358 \\
\hline
\end{tabular}




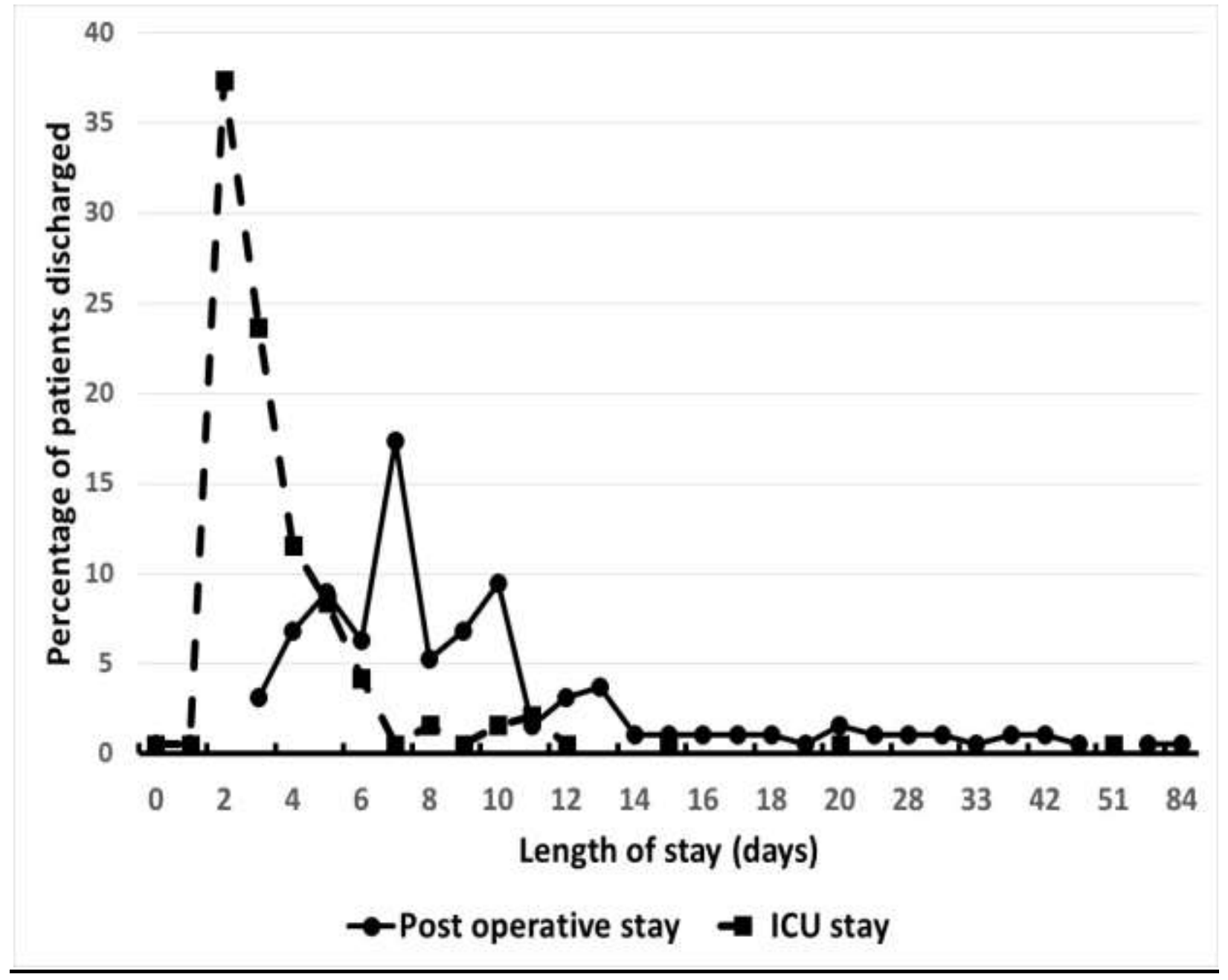

Figure: Distribution of ICU and postoperative length of stay (in days). Abbreviations: ICU = intensive care unit; Post-operative stay $=$ total postoperative stay (include ICU stay) 